\title{
WAVE-CURRENT INTERACTION OVER SEABEDS WITH DIFFERENT ROUGHNESS: A STATISTICAL ANALYSIS
}

\author{
Carla Faraci ${ }^{1}$, Pietro Scandura and Enrico Foti ${ }^{2}$
}

\begin{abstract}
Wave-current flow over seabeds covered with different roughness has been studied in order to deepen the knowledge on the statistical properties of the near-bed velocity. The results of three different experimental campaigns performed in the presence of a sandy bed, a gravel bed and a rippled bed, carried out superimposing a steady current onto an orthogonal wave, have been analysed. The statistics of the current velocity, including the wave effects on the steady current have been investigated. It has been observed that in the absence of waves, the fluctuations of the near-bed velocities closely follow a Gaussian distribution. When waves are also present, in order to obtain consistent near-bed velocity statistics, it is necessary to decouple the velocity events in the current direction by taking into account the sign of the wave velocities. In the latter case, the nature of the distribution functions is influenced by the mass conservation principle. A Gaussian distribution well describes the turbulent fluctuations obtained by removing the phase averaged velocity from the current velocity.
\end{abstract}

Keywords: ripple evolution; asymmetric waves; migration velocity

\section{INTRODUCTION}

In shallow seas, the near bottom flow often consists of waves and slowly varying currents generated by phenomena such as radiation stress, set-up, tides, etc. The thin wave boundary layer at the bottom, driven by the oscillatory nature of the wave orbital velocity, however, strongly affects coexisting currents (Grant \& Madsen, 1979), generating additional turbulence and enhancing the bed shear stresses, leading to increased bottom resistance in the presence of combined flows (Lodahl et al., 1998). The situation is made even more complex by the presence of an erodible bed when bedforms start to appear.

Several researchers contributed to the understanding of wave-current interaction by analysing the combined flow over smooth or rough beds experimentally or numerically.

In the case of collinear or opposing waves and currents, Simons et al. (1992) and Simons et al. (1994) found that the presence of waves induces an important reduction of the mean flow in the upper part of the water column and an increase close to the bed. Lodahl et al. (1998) observed relevant differences in the collinear wave-current interaction depending on whether the combined flow is current dominated or wave dominated. Huang and Mei (2003) developed a theoretical model to predict the wave effects on a turbulent current over smooth or rough beds. They determined a velocity increase in the case of waves propagating with the current and a decrease in the case of opposing flows. Yuan and Madsen (2015) found that in the seabed boundary layer flow, the magnitude of the mean velocity is larger for opposing than for following waves and current.

Fewer studies have been performed in the case of waves and currents interacting at a right angle. Arnskov et al (1993) evaluated the effects of the flow interaction on the bed shear stress over a smooth bed. They did not found a significant non-linear enhancement of the maximum shear stress. Andersen and Faraci (2003) in the presence of a movable bed, analyzed the range of wave - current velocities where bedform geometry could be assumed to be forced only by the oscillatory flow. Musumeci et al (2006) performed an experimental campaign with orthogonal waves plus currents over rough beds. When waves are added onto a current over a bed characterized by a small roughness, they observed an increase of the current flow at the bed; the contrary happening in the case of large roughness.

Lim and Madsen (2016) found an increase of the angle between the mean flow and the waves due to the presence of wave induced mass transport and a decrease of the hydraulic roughness with respect to the current alone case.

Several studies have focused on waves plus currents over rippled beds. Ranasoma and Sleath (1994) performed LDA measurements of orthogonal wave-current flows over fixed ripples. They found that close to the bed measurements do not agree with classical eddy viscosity models, due to the momentum exchange induced by the vortex ejection. Mathiesen and Madsen (1996) found that, in the case of combined flow, roughness is similar to that of a pure wave. Fredsøe et al. (1999), by means of both experimental measurements and a $\kappa-\omega$ turbulence closure model, found an increase up to one

\footnotetext{
${ }^{1}$ Department of Engineering, University of Messina, C.da di Dio, S. Agata 98166 Messina, Italy.

${ }^{2}$ Department of Civil Engineering and Architecture, University of Catania, v.le A. Doria 6, 95125 Catania, Italy.
} 
order of magnitude in the bed roughness when waves are superimposed to a current. According to Faraci et al. (2008) a rippled bed behaves like a macro-roughness towards the current, causing the wave boundary layer to become turbulent. Madsen et al. (2010) observed a veering of near bottom flow towards the ripple crests; moreover in the presence of waves orthogonal to a current a dramatic increase of the roughness was experienced by ripple-parallel currents.

Notwithstanding the above mentioned contribution to the wave-current interaction, to the authors' knowledge little has been done to understand the statistics of the combined flow, which, due to turbulence, fluctuates spatially and temporally around its average values. A quantitative analysis of the statistical properties of the fluid velocities in the presence of a combined wave-current flow could in fact contribute to enlighten some aspects of important bed processes, such as erosion and sediment transport. Indeed, as pointed out by Cheng (2006), most of the works dealing with sediment transport problems, either stochastic or deterministic, take into account the turbulence only through a time averaged velocity or shear stress. A pioneering work in this perspective was performed by Grass and Ayoub (1983), who proposed a probability based model to interpret turbulence induced variations in the instability of a movable bed. The statistics of a turbulent current have been investigated by Kim et al. (1987) by means of a DNS of a turbulent channel flow in the presence of smooth walls to obtain quantitative information on the turbulence structure. Scandura et al. (2016) studied the statistics of the wall shear stress in an acceleration-skewed oscillatory flow. The authors found that the frequency distribution of both the streamwise and the spanwise wall shear stress are generally far from a Gaussian distribution. More recently Willert (2015) employed time resolved PIV techniques for estimating flow statistics, spectra, probability density functions and correlations of a turbulent boundary layer in a wind tunnel. However, none of the previously mentioned works deals with combined wave-current flows.

In this paper the statistics of the current velocity field obtained by superimposing a regular orthogonal wave, in the presence of a sandy bed, a gravel bed and a rippled bed, is reported. More specifically, the study is focused on the effect that orthogonal waves have on the statistics of the current velocity. The analysis is performed on the basis of experimental data already acquired by the authors but never analysed in this perspective. In particular, in previous works (Faraci et al., 2008; Musumeci et al., 2006) only the time-averaged flow velocities have been analysed.

The paper is organized as follows: first the experimental set up and procedure are described, then the analysis of the total near bed horizontal velocity and that of the turbulent velocity fluctuations are reported. The paper ends with the conclusions.

\section{EXPERIMENTAL SET UP AND PROCEDURE}

The experimental facility is located at the Hydraulics Laboratory of the University of Catania and is made up by a wave flume and a recirculating system that allows a uniform current to interact with the waves at a right angle.

The wave flume is $18.00 \mathrm{~m}$ long, $4.00 \mathrm{~m}$ wide and $1.20 \mathrm{~m}$ deep. Regular and irregular waves can be generated by a flap type wavemaker, driven by a pneumatic system and electronically controlled. A plane beach limits the reflection to about $10 \%$ of the incident wave. More details can be found in Faraci et al. (2008) or Faraci et al (2012).

The current is driven by a submerged $11.0 \mathrm{~kW}$ electro-pump, with a maximum discharge of 0.25 $\mathrm{m}^{3} / \mathrm{s}$; in order to damp turbulence, it flows in a series of channels and enters the wave flume at a right angle, through an inlet. The inlet is $2.5 \mathrm{~m}$ wide, the outlet is perfectly mirrored with respect to the inlet. Wave diffraction at the corners of the flume was contained in about ten centimeters from inlet and outlet and it does not influence the measurement area, while passive wave absorbers at the outlet walls minimize spurious wave reflections.

In the central part of the wave flume, an area of $3.5 \mathrm{~m} \mathrm{x} 4 \mathrm{~m}$ has been covered by material of appropriate grain size: for the first campaign, referred to as SB, a fine quartz sand characterized by a $\mathrm{D}_{50}$ of $0.24 \mathrm{~mm}$ was glued onto the bed in a single layer; for the second campaign, referred to as GB, a single layer of marble stones with a median grain size of $\mathrm{D}_{50}=30 \mathrm{~mm}$ was glued on the bed to simulate a gravel bed. More details on these two campaigns can be found in Musumeci et al. (2006). The third campaign, denoted as RB, was carried out placing over the bed a fixed 2D PVC rippled panel, realized by presswork in a unique block. Ripple height was $1.85 \mathrm{~cm}$ and ripple length was $12.5 \mathrm{~cm}$. The bed form characteristics were chosen in such a way to be in agreement with the ripples generated during the experimental campaign performed by Andersen and Faraci (2003) in the presence of orthogonally superimposed waves and currents and the same ratio between current and wave orbital velocities. The RB campaign has been reported in Faraci et al. (2008). 
The surface elevation was measured by means of several resistance wave gauges located along the flume. In addition a Sontek micro Acoustic Doppler Velocimeter (micro-ADV), mounted on a movable carriage, was used to measure the three velocity components. The sampling volume is a cylinder with a height of $9 \mathrm{~mm}$ and a volume of $0.3 \mathrm{~cm}^{3}$, located $5 \mathrm{~cm}$ below the transmitter.

Due to the dimensions of the measuring volume, the closest point to the bed was located about 0.45 $\mathrm{cm}$ above the bottom. Thus velocity measurements were not gathered either within the thin wave bottom boundary layer $(\mathrm{O}(\sim 1 \mathrm{~mm}))$, and between wave crest and level $5 \mathrm{~cm}$ below the wave trough. The adopted sampling frequency was $30 \mathrm{~Hz}$.

The adopted reference system has been chosen in such a way that $\mathrm{x}$ follows the steady current, $\mathrm{y}$ is in the direction of the wave propagation, $\mathrm{z}$ is positive upward and the origin is located at the bottom in the SB and GB experiments and at the trough level in the rippled bed (RB) tests.

In Figure 1 a picture of the wave plus current experimental flume with the fixed rippled bed is reported.

The experimental procedure can be synthesized as follows:

1. first regular waves are generated until steady conditions are reached;

2. wave characteristics and velocity profiles are gathered at the measuring stations;

3. the wavemaker is stopped and the flow rate is fixed, running the recirculating system until a uniform current is established within the wave tank;

4. current only velocity profiles are gathered;

5. waves are superimposed to existing current and wave current velocity profiles are acquired after steady conditions are reached.

In order to verify that a steady condition has been attained, the mean levels in all the tanks have been monitored; in the presence of currents this stage was usually reached after 2-3 hours after starting the apparatus.

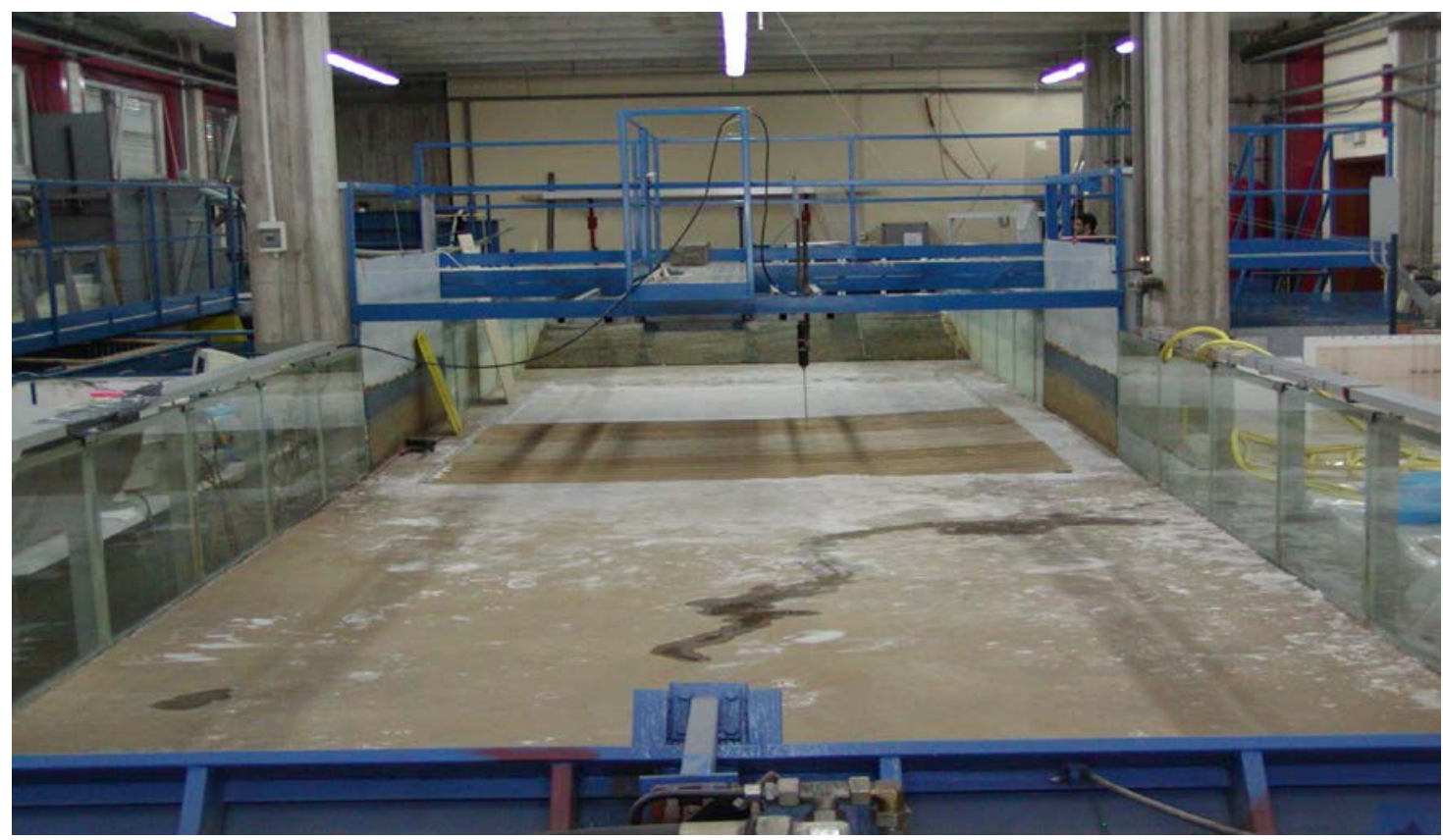

Figure 1 Picture of the experimental set up with the PVC rippled bed .

The three sets of experiments, previously indicated as SB, GB and RB, are discussed in order to highlight some statistical properties of the flow. Wave conditions in all the experiments are characterized by periods between $0.8 \mathrm{~s}$ and $1.6 \mathrm{~s}$ and two different wave heights, namely $0.085 \mathrm{~m}$ and $0.105 \mathrm{~m}$. Water depth $\mathrm{D}$ is constant in all the tests and equal to $0.3 \mathrm{~m}$, while the depth averaged current velocities are $0.045 \mathrm{~m} / \mathrm{s}, 0.07 \mathrm{~m} / \mathrm{s}$ and $0.10 \mathrm{~m} / \mathrm{s}$. Current only, wave only and wave plus current flow conditions have been considered. In Musumeci et al. (2006) a detailed report on the spatial homogeneity of the wave current interaction in the central part of the channel is reported. Within this area a single measurement station located along the median axis between inlet and outlet, $2.5 \mathrm{~m}$ far 
away from the inlet, has been considered for the SB and GB campaigns. For RB campaign five measuring stations were considered along the ripple profile, two of them at the two adjacent crests, one at the trough and the other two between crest and trough. A total number of 17 experiments have been performed for both SB and GB tests, 29 for the RB one. In each test the vertical profiles of the three velocity components, $\mathrm{V}_{\mathrm{x}}, \mathrm{V}_{\mathrm{y}}$ and $\mathrm{V}_{\mathrm{z}}$ in the $\mathrm{x}, \mathrm{y}$ and $\mathrm{z}$ directions have been acquired.

\section{ANALYSIS OF THE RESULTS}

\section{Frequency distributions of the near bed mean flow velocity}

The statistical distributions of the velocity components in the $\mathrm{x}$ direction have been analyzed. First of all the frequency distribution of the bed velocity has been obtained by counting the number of occurrences $\mathrm{N}$ in $\mathrm{n}$ classes of $v_{x}$, divided by the total number of occurrences; here $\mathrm{n}$ has been chosen equal to 40 , because such a value is high enough to provide a good representation of the whole velocity distribution but adequate to contain a proper number of events in each class.

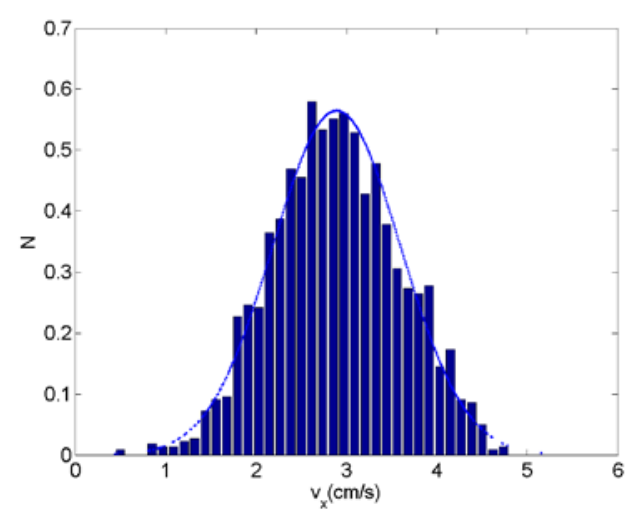

(a)

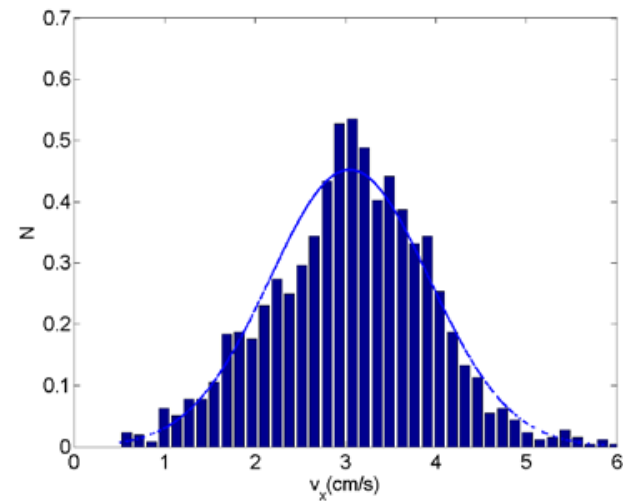

(b)

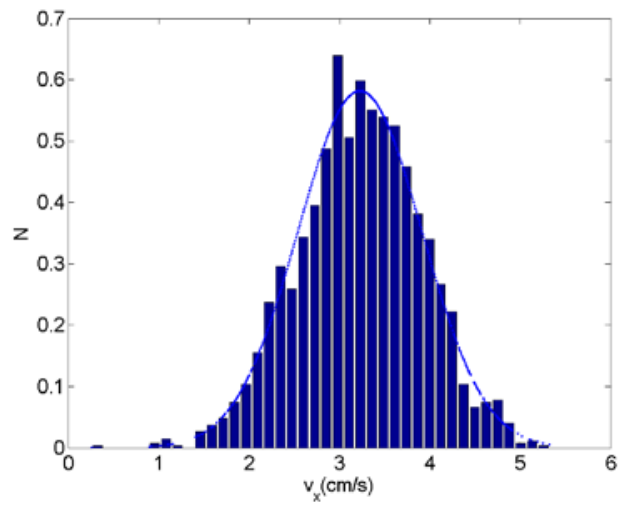

(c)

Figure 2 Frequency distribution of $V x$ in the current only case at a point $0.5 \mathrm{~cm}$ far from the bed for a flow rate of $0.045 \mathrm{~m} / \mathrm{s}$ and the following bed roughness: (a) SB; (b) GB; (c) RB (trough). The Gaussian PDF that best fits the data is also shown.

Figure 2 shows the probability distribution for one of the current only cases (mean velocity $\mathrm{V}$ equal to $0.045 \mathrm{~m} / \mathrm{s}$ ) at the measuring point located about $0.5 \mathrm{~cm}$ far from the bed; each plot corresponds to a different roughness condition, i.e. $\mathrm{SB}, \mathrm{GB}$ and $\mathrm{RB}$ respectively. It can be observed that in the case of sandy bed the PDF is symmetric and the skewness is approximately zero. In the gravel and rippled bed cases the behaviour is rather similar to each other and the distributions show a negative skewness.

When waves are added on the existing current, the flow assumes more complex features. In Figure 3 , a wave characterized by a height $\mathrm{H}=0.085 \mathrm{~m}$ and a period $\mathrm{T}=1.2 \mathrm{~s}$ is superimposed on the steady flow with a depth averaged velocity $\mathrm{V}=0.045 \mathrm{~m} / \mathrm{s}$. It is possible to observe that the agreement between the frequency distribution of the current velocity and the Gaussian probability density function dramatically worsens. In particular two main peaks are visible in sand and gravel bed cases, while in the 
rippled bed test, where the measurement point is located in the bedform trough and thus sheltered by the ripple lee side, such a feature is less evident.

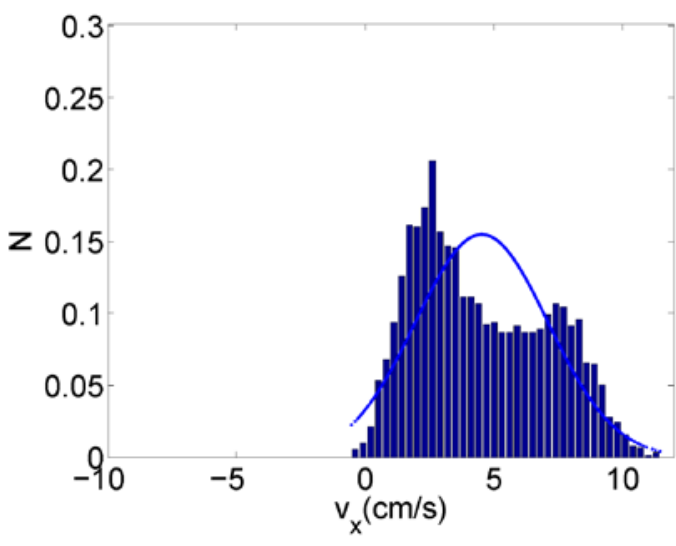

(a)

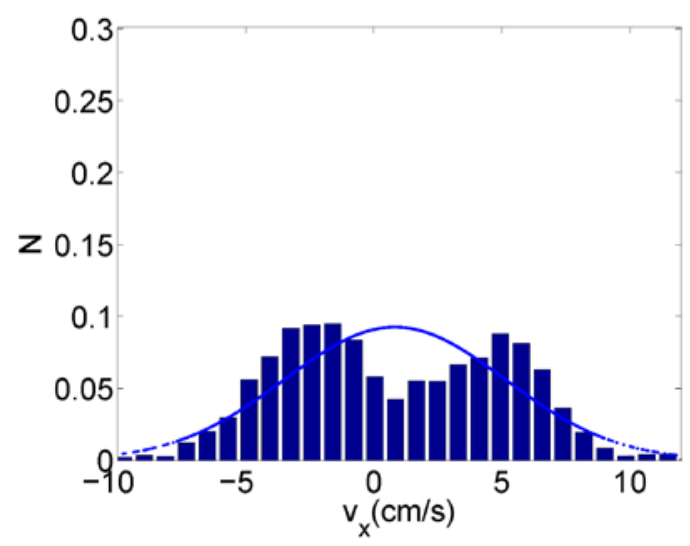

(b)

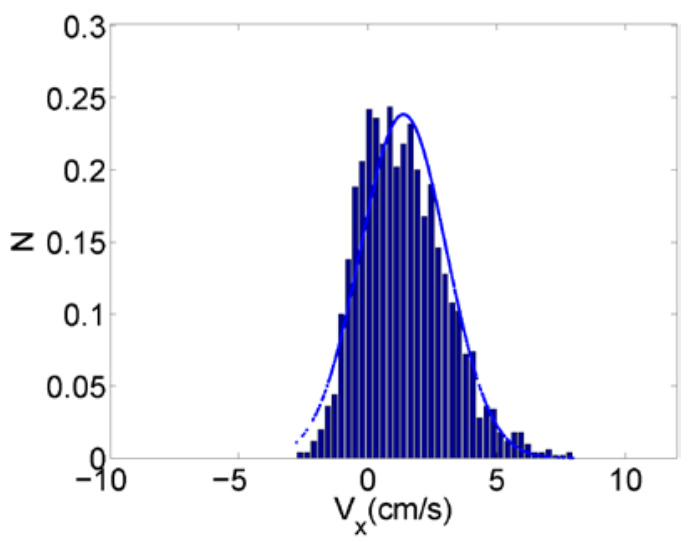

(c)

Figure 3 Frequency distribution of $\mathrm{Vx}$ in the wave plus current case at a point $0.5 \mathrm{~cm}$ far from the bed for a depth averaged velocity $V=0.045 \mathrm{~m} / \mathrm{s}, \mathrm{H}=0.085 \mathrm{~m}, \mathrm{~T}=1.2 \mathrm{~s}$, and the following bed roughness: (a) $S B$; (b) GB; (c) RB (trough). A Gaussian PDF is also superimposed.

In order to understand the origin of such double peaks, the velocity data were decoupled in two classes the first corresponding to positive values of the wave velocity component (i.e. to the passage of a wave crest, or onshore directed wave velocities $V_{y}$ ) hereinafter referred to as $v_{x}^{y+}$, the second corresponding to negative values of the wave velocity component (i.e. to the trough passage, or offshore directed wave velocities $V_{y}$ ) hereinafter referred to as $v_{x}^{y-}$. The result of such a procedure is shown in Figure 4 for the rippled bed case, wave height $\mathrm{H}=0.085 \mathrm{~m}$, period $\mathrm{T}=1.2 \mathrm{~s}$ and mean velocity $\mathrm{V}=0.045$ $\mathrm{m} / \mathrm{s}$. The four plots are referred to the measurement points located along the ripple profile, between two adjacent crests.

The distributions of $v_{x}^{y+}$ and $v_{x}^{y-}$ are rather separated one from the other, and the peak of the PDF of $v_{x}^{y+}$ always occurs at smaller velocities than that of $v_{x}^{y-}$.

This evidence can be explained by recalling that $\mathrm{V}_{\mathrm{y}}>0$ occurs under the wave crest; at this location the water depth is larger and thus the current velocity decreases, the opposite happening under the wave trough. An exception is the point between the crest and the trough, where the leeward ripple side is interested by a high anticlockwise vorticity. This means that a water particle coming from the accelerated seaward side is pulled down leeward by the presence of the recirculating cell: here the current velocity is thus higher than expected because the water particle comes from a region farther from the bed than the place where the measuring point is located. This mechanism leads to level the values of $v_{x}^{y+}$ and $v_{x}^{y-}$. 


\section{Statistics of the turbulent velocity fluctuations}

The turbulent velocity fluctuations $v_{x}^{\prime}$ have been computed by subtracting to $v_{x}$ the phase averaged velocity in the current direction. Figure 5 shows the probability distribution of the turbulent component $v_{X}^{\prime}$ in a wave plus current condition characterized by a depth averaged velocity $\mathrm{V}=0.045 \mathrm{~m} / \mathrm{s}$, and a wave with $\mathrm{H}=0.105 \mathrm{~m}, \mathrm{~T}=1.2 \mathrm{~s}$, for the three bottom roughness cases $\mathrm{SB}$, GB and $\mathrm{RB}$ respectively. Such a component shows a different behavior with respect to $v_{x}$. Indeed in the probability density functions there is no evidence of double peaks, while the Gaussian distribution describes very well the distribution of the turbulent fluctuations in the sandy bed case. This probably depends on the fact that $v_{x}^{\prime}$ does not contain the fluctuating velocity induced by the wave motion although this motion affects the turbulent component. In the gravel and rippled bed cases, even though double peaks do not occur, the distributions are more peaked than the normal one.

The largest turbulent fluctuations are of about $5 \mathrm{~cm} / \mathrm{s}$ in the SB and RB cases, while they are stronger in the GB case where form induced turbulence highly influences the near bottom flow.

The standard deviation of the velocity fluctuations provides a measure of the width of the probability distribution. Figure 6a shows the standard deviation for a current only condition with a depth averaged velocity $V=0.045 \mathrm{~m} / \mathrm{s}$, while Figure $6 \mathrm{~b}$ shows the waves plus current conditions having the same mean velocity superimposed to a wave with $\mathrm{H}=0.085 \mathrm{~cm} / \mathrm{s}$ and $\mathrm{T}=1.2 \mathrm{~s}$.

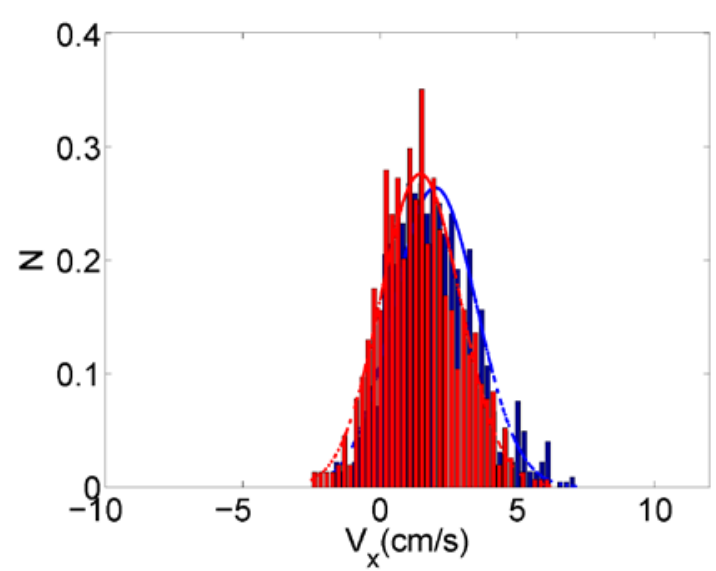

(a)

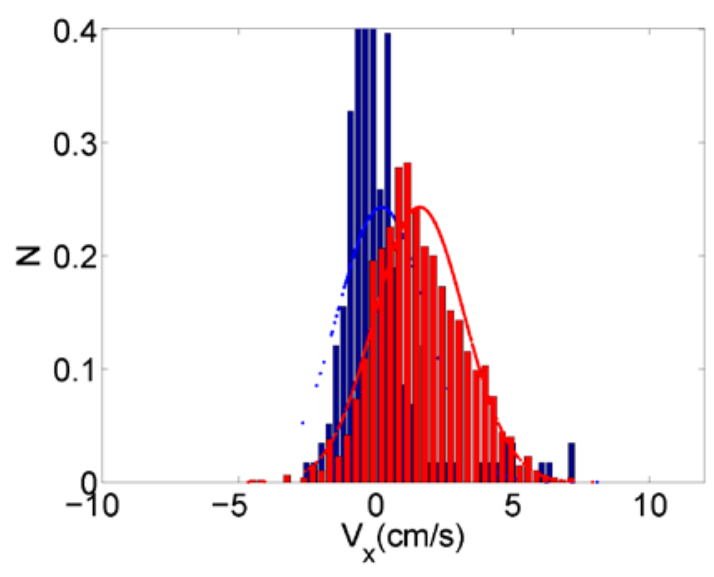

(c)

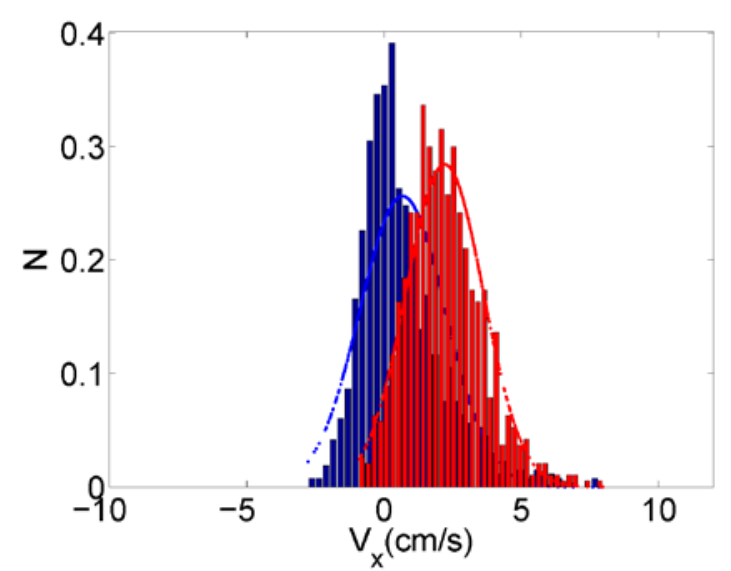

(b)

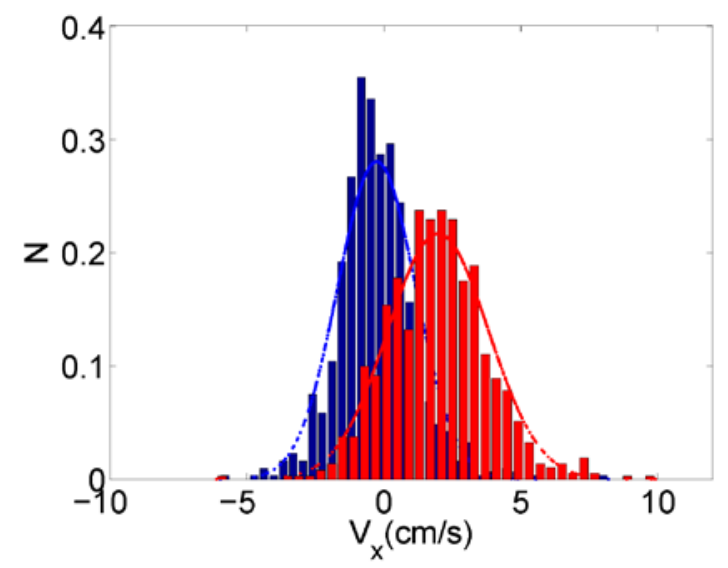

(d)

Figure 4 Frequency distribution of $v_{x}^{y+}$ and $v_{x}^{y-}$ for the rippled bed case: (a) intermediate between crest and trough; (b) trough; (c) intermediate between trough and crest; (d) crest. The measuring point is located 0.5 $\mathrm{cm}$ far from the bottom. Same test conditions and symbols as in Fig. 5. Red bar plot: current velocities acquired when the wave velocity is negative $\left(v_{x}^{y-}\right)$. Blue bar plot: current velocities acquired during the passage of positive wave velocities $\left(v_{x}^{y+}\right)$. The corresponding Gaussian PDFs are also superimposed. 
It can be observed that the standard deviation for the gravel bed case is the largest. Indeed, as stated before, the turbulence is highly affected by the large roughness, thus causing an important increase of the standard deviation with respect to the other two investigated cases. The standard deviation shows that the turbulence is higher close to the bed in the case of current only.

The addition of an orthogonal wave to a current causes a large increase of the standard deviation of the turbulent fluctuations. Close to the bottom, for both ripple and sand bed cases, the standard deviation increases from about 0.8 for the current only case up to about 1.2 for the waves plus current. In the gravel bed case, at the bottom it doubles the value due to the current only. Furthermore, in the waves plus current case the turbulence intensity is rather constant along the depth with the exception of the gravel bed case for which the intensity of the turbulence is rather large close to the bed.

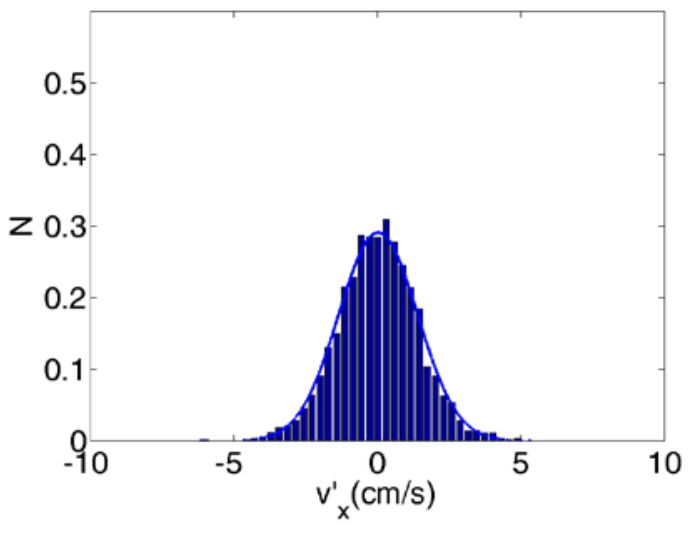

(a)

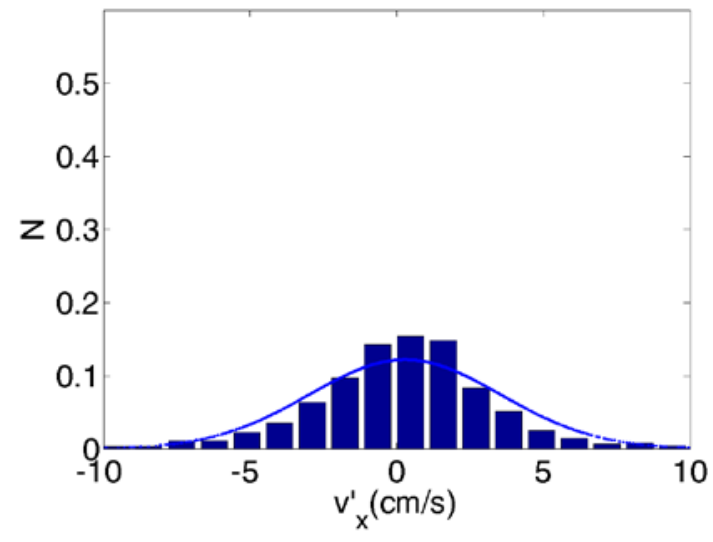

(b)

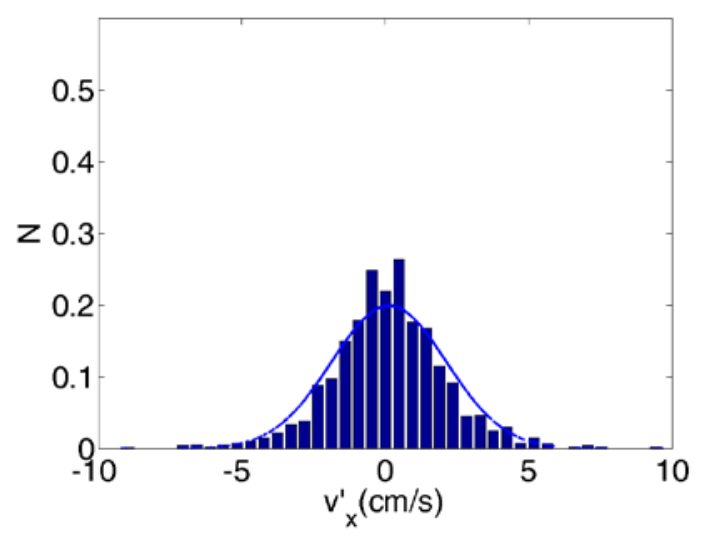

(c)

Figure 5 Frequency distribution of turbulent fluctuations $v_{X}^{\prime}$ in the wave plus current case at a point $0.5 \mathrm{~cm}$ far from the bed for a flow rate of $0.045 \mathrm{~m} / \mathrm{s}, \mathrm{H}=0.105 \mathrm{~m}, \mathrm{~T}=1.2 \mathrm{~s}$, and the following bed roughness: (a) SB; (b) GB; (c) RB (trough). A Gaussian PDF is also superimposed.

Figure 7 shows the skewness and flatness of fluctuating component $v_{x}^{\prime}$ for a wave plus current case characterized by a mean flow rate of $\mathrm{V}=0.045 \mathrm{~m} / \mathrm{s}$, and a wave characterized by $\mathrm{H}=0.105 \mathrm{~m}$ and $\mathrm{T}=1.2$ for all the roughness conditions. These statistics are defined as shown in equation (1) where an overbar denotes a time average. It is worth to recall that a normal distribution has skewness equal to zero and flatness equal to 3 .

$$
\text { Skewness }=\frac{\overline{v_{x}^{\prime 3}}}{{\overline{v_{x}^{\prime 2}}}^{3 / 2}} \quad \text { Flatness }=\frac{\overline{v_{x}^{\prime 4}}}{{\overline{v_{x}^{\prime 2}}}^{2}}
$$


The skewness is mainly positive in the lower part of the water column for most of the measured points in the case of sandy and gravel bed, while it becomes negative in the upper part of the measured column. In the rippled bed case it remains approximately equal to zero for most of the water column, showing a slightly positive skewness in the upper part of the column.

The flatness does not show significant variations among the three investigated roughness conditions. In particular it takes large values near the bottom, while moving away from the bottom it assumes values close to 3 . In the sand bed case however, at some higher elevations the flatness assumes values larger than 3 .

Looking at the results shown in Figure 7, one may argue that close to the bed the distribution is far from a normal distribution in the gravel and rippled bed cases, as already observed previously, while it better follows the Gaussian distribution in the sand bed case. The normal distribution may be attained far from the bed where the skewness is close to zero and the flatness is close to 3.

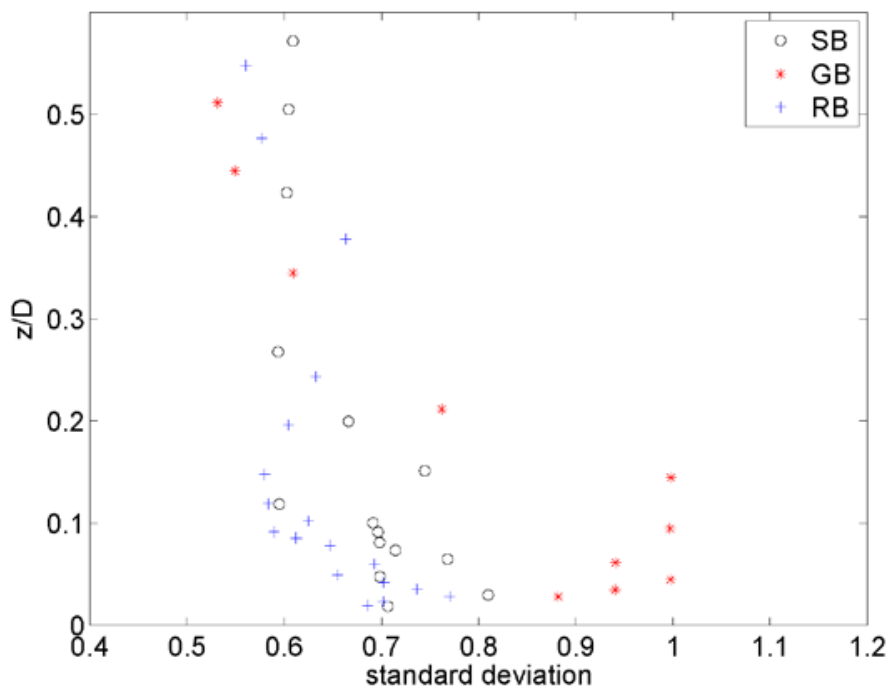

(a)

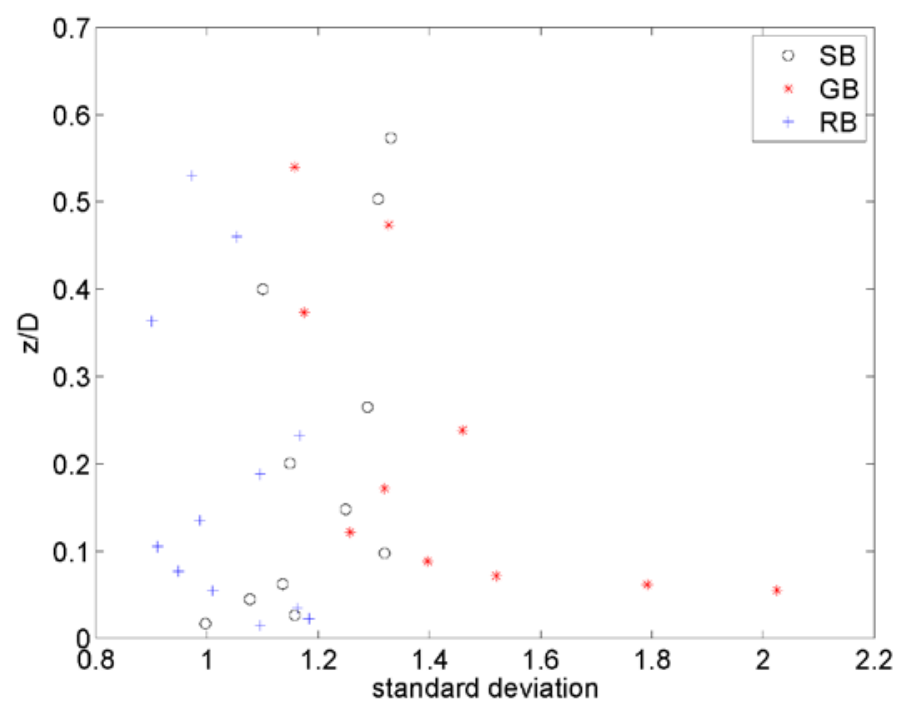

(b)

Figure 6 Vertical profiles of standard deviation of the fluctuating component $v_{X}^{\prime}$; (a) current only case $(\mathrm{V}=0.045 \mathrm{~m} / \mathrm{s})$ (b) wave plus current case $(\mathrm{V}=0.045 \mathrm{~m} / \mathrm{s} ; \mathrm{H}=0.085 \mathrm{~m} ; \mathrm{T}=1.2 \mathrm{~s})$. 


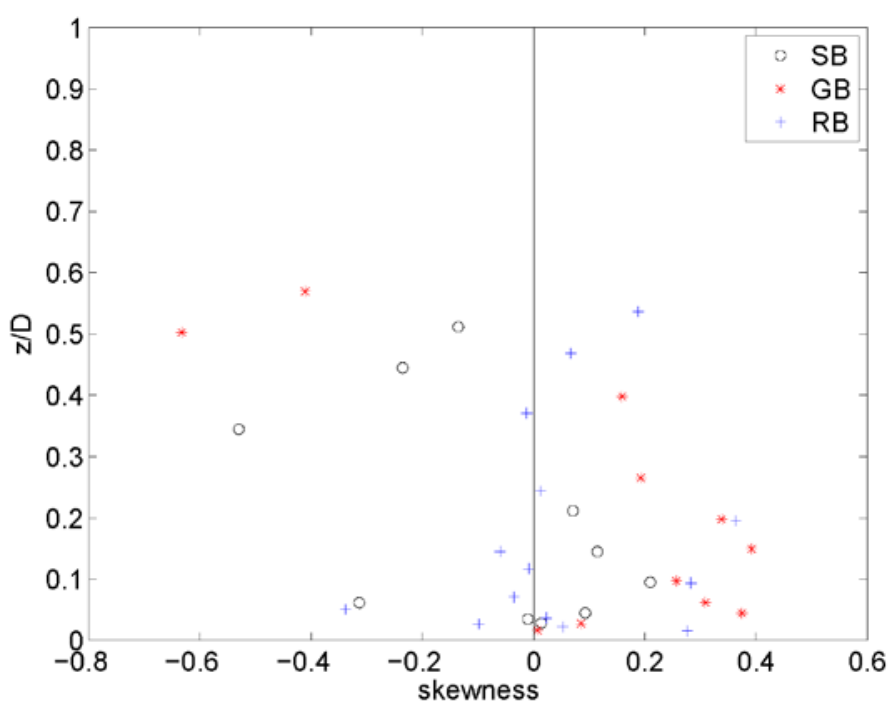

(a)

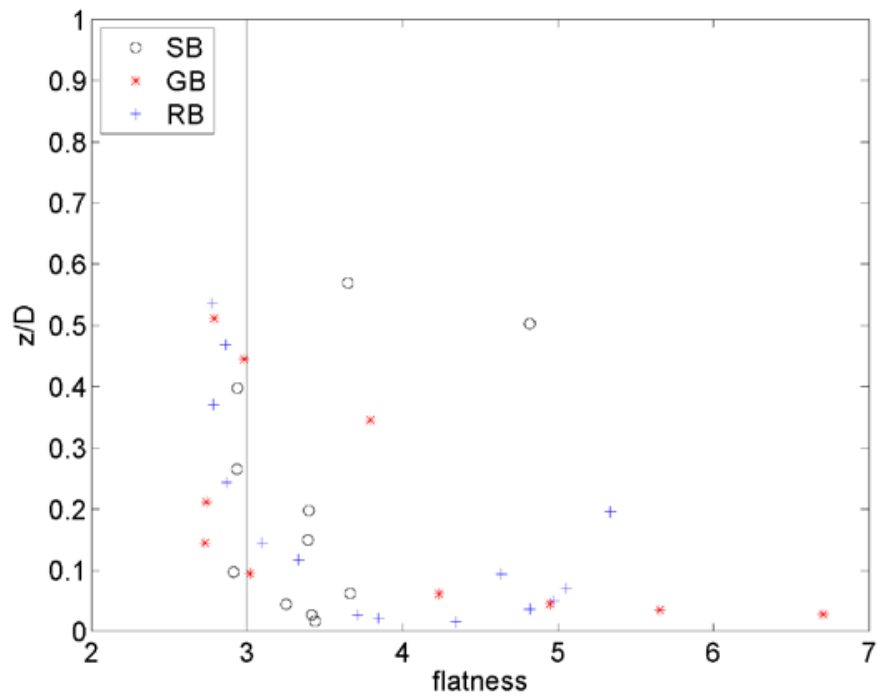

(b)

Figure 7 Vertical profiles of: (a) skewness and (b) flatness of the fluctuating component $v_{x}^{\prime} \cdot(\mathrm{V}=0.045 \mathrm{~m} / \mathrm{s}$; $\mathrm{H}=0.105 \mathrm{~m} ; \mathrm{T}=1.2 \mathrm{~s})$.

\section{CONCLUSIONS}

The present paper described the analyses performed on the data acquired in three experimental campaigns performed in a wave plus current environment in the presence of three different bed roughness, namely a sandy bed, a gravel bed and a rippled bed.

The near bed velocity in the current direction, acquired by means of a micro-ADV, has been considered in order to understand how the addition of a wave onto an existing current could affect the total flow. It has been found that the probability density function of the near bed velocity, in the current only case, is reasonably similar to the normal distribution, with slight differences between sand, gravel and rippled bed.

If a wave is superimposed onto the current, the distribution function shows double peaks, determining a loose of agreement with the normal distribution. It has been observed that if the near bed velocity is split in two classes of events, occurring in concurrence with positive or negative wavedirected velocities (i.e. onshore or offshore directed wave flow), two different frequency distributions can be observed. The peak of the distribution of the current velocity associated with onshore directed 
wave velocities $V_{x}^{y+}$ always occurs at smaller velocities than that of $v_{x}^{y-}$. This can be explained by recalling the mass conservation principle and taking into account that under the wave crest the total depth is larger than under the trough.

Finally the statistical analysis of the turbulent velocity fluctuations obtained by removing from the current velocity its phase average, which contains oscillations induced by the waves, showed that the double peaks disappear from distributions; the latter is similar to the normal distribution in the sand bed case. In the gravel and rippled bed cases the distributions are symmetric, but they exhibit a flatness significantly larger than 3 .

\section{ACKNOWLEDGMENTS}

This research has been partially funded by the Italian Ministero dell'Istruzione, dell'Università e della Ricerca through the PRIN 2012 Project 'Hydromorphodynamic modeling of coastal processes for engineering purposes'.

\section{REFERENCES}

Andersen, K. H., \& Faraci, C. (2003). The wave plus current flow over vortex ripples at an arbitrary angle. Coastal Engineering, 47, 431-441. (doi: 10.1016/S0378-3839(02)00158-8)

Arnskov, M. M., Fredsøe, J., \& Sumer, B. M. (1993). Bed shear stress measurements over a smooth bed in three-dimensional wave-current motion. Coastal Engineering, 20, 277-316.

Cheng, N. S. (2006). Influence of shear stress fluctuation on bed particle instability. Physics of Fluids, 18(9).

Faraci, C., Foti, E., Marini, A., \& Scandura, P. (2012). Waves plus currents crossing at a right angle: Sandpit case. Journal of Waterway, Port, Coastal, and Ocean Engineering, 138(5), 339-361. (doi: 10.1061/(ASCE)WW.1943-5460.0000140)

Faraci, C., Foti, E., \& Musumeci, R. (2008). Waves plus currents crossing at a right angle: the rippled bed case. Journal of Geophysical Research, 113(C07018), 1-26. (doi: 10.1029/2007JC004468)

Fredsøe, J., Andersen, K. H., \& Sumer, B. M. (1999). Wave plus current over a ripple-covered bed. Coastal Engineering, 38, 177-221.

Grant, W. D., \& Madsen, O. S. (1979). Combined wave and current interaction with a rough bottom. Journal of Geophysical Research., 84(C4), 1797-1808.

Grass, A. J., \& Ayoub, R. N. M. (1983). Bed load transport of fine sand by laminar and turbulent flow. In 18th int. conf. on coastal engineering (pp. 1589-1599). ASCE.

Huang, Z., \& Mei, C. C. (2003). Effects of surface waves on a turbulent current over a smooth or rough seabed. Journal of Fluid Mechanics., 497, 253-287.

Kim, J., Moin, P., \& Moser, R. (1987). Turbulence statistics in fully developed channel flow at low reynolds number. Journal of Fluid Mechanics, 177, 133-166.

Lim, K. Y., \& Madsen, O. S. (2016). An experimental study on near-orthogonal wave-current interaction over smooth and uniform fixed roughness beds. Coastal Engineering, 116, 258- 274.

Lim, K. Y., Madsen, O. S., \& Cheong, H. F. (2012). Current characteristics in the presence of near orthogonal waves. In 33rd int. conf. on coastal engineering. ASCE.

Lodahl, C. R., Fredsøe, J., \& Sumer, B. M. (1998). Turbulent combined oscillatory flow and current in a pipe. Journal of Fluid Mechanics, 373, 313-348.

Madsen, O. S., Negara, A. S., Lim, K. Y., \& Cheong, H. F. (2010). Near-bottom flow characteristicsof currents at arbitrary angle to 2d ripples. In 32nd int. conf. on coastal engineering.

Mathiesen, P. P., \& Madsen, O. S. (1996). Waves and current over a fixed ripples bed: 1. bottom roughness experienced by currents in the presence of waves. Journal of Geophysical Research, 101(C7), 16543-16550.

Musumeci, R. E., Cavallaro, L., Foti, E., Scandura, P., \& Blondeaux, P. (2006). Waves plus currents crossing at a right angle. Experimental investigation. Journal of Geophysical Research, 111(C07). (doi: 10.1029/2005JC002933)

Ranasoma, K. I. M., \& Sleath, J. F. A. (1994). Combined oscillatory and steady flow over ripples. Journal of Waterway, Port, Coastal and Ocean Engineering, 120(4), 331-346.

Scandura, P., Faraci, C., \& Foti, E. (2016). A numerical investigation of acceleration-skewed oscillatory flows. Journal of Fluid Mechanics, 808, 576613. 
Simons, R. R., Grass, T. J., \& Mansour-Tehrani, M. (1992). Bottom shear stresses in the boundary layer under waves and currents crossing at right angle. In 23rd int. conf. on coastal engineering (Vol. 1, pp. 604-617). ASCE.

Simons, R. R., Grass, T. J., Saleh, W. M., \& Mansour-Tehrani, M. (1994). Bottom shear stresses under random waves with a current superimposed. In 24th int. conf. on coastal engineering. ASCE.

Willert, C. E. (2015). High-speed particle image velocimetry for the efficient measurement of turbulence statistics. Experiments in Fluids, 56(17).

Yuan, J., \& Madsen, O. (2015). Experimental and theoretical study of wave-current turbulent boundary layers. Journal of Fluid Mechanics, 765, 480523. 